\title{
Introduction to the focussed series on "Current Management Aspects in Adult Congenital Heart Disease (ACHD): Part IV"'
}

Medical care for patients with congenital heart disease (CHD) has currently reached a high, unprecedented level. Children with CHD now reach adulthood in more than $95 \%$ of industrialized countries, and the number of adults with congenital heart defects (ACHD) is estimated at 500 million worldwide.

However, because most CHD's are repaired rather than completely corrected, anatomic and functional residua and sequelae often remain. All patients with CHD are and remain chronically ill and require lifelong experienced and dedicated follow-up. For this purpose, it is necessary that the physicians providing care are well educated and trained about the potential problems:

Cardiac defect-specific residuals and sequelae such as heart failure, arrhythmias, pulmonary vascular disease, aortic disease, infective endocarditis, or concomitant acquired organ disease affect the quality of life, performance, work capacity, and mental health of ACHD.

To ensure that the health, well-being, quality of life, and survival of EMAH are as favorable as possible, adequate, lifelong, medical care is one of the most important determinants. However, this requires that all physicians providing care are up to date with the latest knowledge and are also continuously educating themselves in this area.

In this 4th volume of a series on ACHD, international authors again present new research findings and convey relevant aspects of ACHD care.

Initially, current data from three large registries are presented, the Compera Registry, one of the world's largest registries on pulmonary hypertension in CHD, as well as the Hungarian CSONGRAD Registry and the MAGYAR-Path Study and the German National Registry for CHD.

For long-term follow-up, recent data on tetralogy of Fallot, transposition of the great arteries after Senning and Mustard procedures, and Ebstein's anomaly are presented.

Important aspects of long-term care deal with anticoagulation management, use of implantable loop recorders for the management of cardiac arrhythmias, pregnancy or the management of rare catheter complications.

The contributions on the application of modern imaging MRI-technologies deal with the analysis of vascular anatomy and hemodynamics, the assessment of aortic diameter and guidance of catheter interventions.

Other important and sometimes neglected topics of long-term care in congenital heart such as Body modification, including piercing and tattooing, infective endocarditis or medical rehabilitation are also discussed.

We also wish the present series of the CDT Journal, which reports on important, new and also practice-relevant aspects of ACHD care, much success

Again we would like to thank the CDT Journal and especially Prof. Paul Schoenhagen, Editor-in-Chief, for their dedication to the field of ACHD and for giving the topic of "Adult Congenital Heart Disease" space for scientific publications. We are already looking forward to working with them on the conception of a following volume.

\section{Acknowledgments}

Funding: None.

\section{Footnote}

Provenance and Peer Review: This article was commissioned by the editorial office, Cardiovascular Diagnosis and Therapy for the series "Current Management Aspects in Adult Congenital Heart Disease (ACHD): Part IV". The article did not undergo external peer review.

Conflicts of Interest: All authors have completed the ICMJE uniform disclosure form (available at https://dx.doi.org/10.21037/ cdt-21-703). The series "Current Management Aspects in Adult Congenital Heart Disease (ACHD): Part IV" was 
commissioned by the editorial office without any funding or sponsorship. HK serves as an unpaid editorial board member of Cardiovascular Diagnosis and Therapy from February 2018 to January 2022. YVK serves as an unpaid editorial board member of Cardiovascular Diagnosis and Therapy from October 2018 to September 2022. KN serves as an unpaid editorial board member of Cardiovascular Diagnosis and Therapy from October 2018 to September 2022. All authors served as the unpaid Guest Editors of the series. The authors have no other conflicts of interest to declare.

Ethical Statement: The authors are accountable for all aspects of the work in ensuring that questions related to the accuracy or integrity of any part of the work are appropriately investigated and resolved.

Open Access Statement: This is an Open Access article distributed in accordance with the Creative Commons AttributionNonCommercial-NoDerivs 4.0 International License (CC BY-NC-ND 4.0), which permits the non-commercial replication and distribution of the article with the strict proviso that no changes or edits are made and the original work is properly cited (including links to both the formal publication through the relevant DOI and the license). See: https://creativecommons.org/licenses/by-nc$\mathrm{nd} / 4.0 \%$.

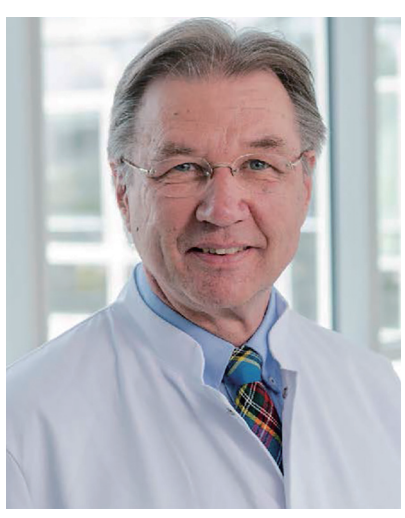

Harald Kaemmerer

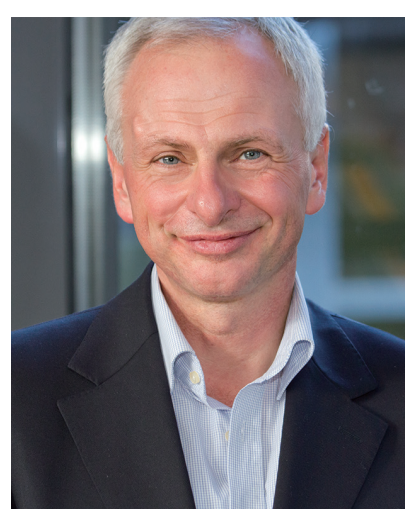

Yskert von Kodolitsch

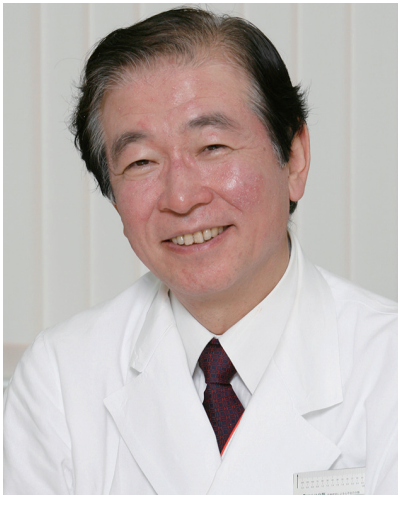

Koichiro Niwa

Harald Kaemmerer, MD, VMD

Professor of Internal Medicine/Cardiology, Department of Congenital Heart Disease and Pediatric Cardiology, German Heart Center Munich, Technical University Munich, Munich, Germany. (Email: Kaemmerer@dhm.mbn.de)

Yskert von Kodolitsch, MD, MBA Clinic of Cardiology, University Clinic Hamburg-Eppendorf, Hamburg, Germany. (Email: kodolitsch@uke.de) Koichiro Niwa, MD, PhD Executive Advisor, Cardiovascular Center, St. Luke’s International Hospital, Tokyo, Japan. (Email: kniwa@aol.com) Submitted Nov 08, 2021. Accepted for publication Nov 25, 2021. doi: $10.21037 / \mathrm{cdt}-21-703$

View this article at: https://dx.doi.org/10.21037/cdt-21-703

Cite this article as: Kaemmerer H, von Kodolitsch Y, Niwa K. Introduction to the focussed series on "Current Management Aspects in Adult Congenital Heart Disease (ACHD): Part IV". Cardiovasc Diagn Ther 2021;11(6):1253-1254. doi: 10.21037/ cdt-21-703 